This is an Author's Accepted Manuscript of an article published in SPORT IN SOCIETY:

CULTURES, COMMERCE, MEDIA, POLITICS, vol. 16, no. 10, 2013, copyright Taylor \& Francis, available online at: http://www.tandfonline.com/10.1080/17430437.2013.790896.

\title{
Enter the Discourse: Exploring the Discursive Roots of Inclusivity in Mixed-Sex Martial Arts
}

\author{
Alex Channon \\ Department of Secondary Education, University of Greenwich, London, UK \\ Corresponding Author: \\ Dr. Alex Channon, School of Education, University of Greenwich, Mansion Site, Bexley Road, \\ London SE9 2PQ \\ Tel: +44 (0)20 83318255 \\ Email: a.g.channon@gre.ac.uk
}




\title{
Enter the Discourse: Exploring the Discursive Roots of Inclusivity in Mixed-Sex Martial Arts
}

\begin{abstract}
In this paper I explore the discursive roots of inclusivity in mixed-sex martial arts training in the UK. Based on data from two qualitative studies conducted in the English East Midlands, I briefly account for the level of integration among several martial arts schools, before focusing on the unique meanings of martial arts which appeared to facilitate the normalization of this integration among participants. Drawing on insights from queer feminist theory, I argue that the discursive framing of martial arts in contemporary Western culture is significant in the generation and normalization of mixed-sex inclusivity in these settings. As such, I suggest that scholars interested in the potential of sex-integrated sports for challenging dominant sexual hierarchies should be attentive to the unique discursive meanings of specific sports cultures, which may be generative of possibilities for radical forms of embodiment and practice.
\end{abstract}

\section{Introduction}

Issues pertaining to the restriction of women's and girls' access to sports, along with the concurrent meanings of male-dominated and male-centred sport, have previously been central to the efforts of feminist research and writing in the field of sports studies. Broadly concerned with challenging inequity whilst re-defining the meanings of sport and the athletic woman, such work has also forwarded the promise of sport as a potentially profound site for women's liberation and empowerment. ${ }^{1}$ Within this framework, feminist researchers have begun to explore the phenomenon of mixed-sex participation in sport. While this is currently an emerging field of interest within the broader feminist sociology of sport, a small number of studies of specific activities, including softball, soccer, cheerleading, and judo, as well as more generalized investigations, have appeared across a variety of academic journals in recent years. ${ }^{2}$ McDonagh and Pappano's book, Playing with the Boys, forwarded an argument common among such works: that mixed-sex sports can provide unique, transformative experiences to participants, posing clear challenges to the discourses of male superiority otherwise embedded in many aspects of contemporary sports culture. ${ }^{3}$ This is principally achieved through the implications of physical equality between the sexes which integrated sports represent, articulated via their unique relationship to the sexed body and showcasing of its evident potentials.

In contemporary feminist theory, such understanding of the sexed body takes a place of prominence as a key aspect of debates concerning the socially-constructed character of gender, itself an important element of the legitimation of patriarchy. Institutions which emphasize differences between male and female bodies - such as differently 'gendered' sports cultures - are seen as important sites for the naturalization of inequitable sexual difference, particularly when they cause men and women to embody those differences, 
making them appear biological and thus, 'natural'. ${ }^{4}$ As such, 'queer' feminist theorists, such as Judith Butler, Donna Haraway and Elizabeth Grosz, have suggested that gender, as a culturally-mandated set of performances, causes individuals' bodies to be shaped according to the discursive limits and imperatives which it sets out for them. ${ }^{5}$ By 'doing' their socially legitimated gender, male bodies accrue 'masculine' traits while female bodies become 'feminine', over-emphasizing and distorting whatever biologically-predestined differences may exist between differently sexed bodies. In this regard, the very idea of there being two 'natural', totally distinctive sexual groups is suspect, as the effect of culturally-constructed, performatively embodied gender discourse effectively obscures similarities between bodies in the process of constructing this binary, and hierarchal, system of difference. And because segregated sport is largely predicated upon discursive constructions of essential sex difference, as well as upon emphasizing and showcasing men's positioning as superior to women within this system, it has been argued that 'gender divisions and men's superiority are more naturalized in sport than perhaps any other institution' in contemporary society. ${ }^{6}$

Such theory suggests, however, that physical practices which do away with sex as an organizing category, which 'fall outside' of typical gender discourse, hold out the possibility to subvert this hierarchal system. ${ }^{7}$ For when men and women are not bound by the limits of a discourse emphasizing such essential and predestined differences, and thus act in ways which stand outside of its typical dictates, they are able to realize the potentials of each other's sexed bodies in new ways. This then opens opportunities for the construction of a diversity of alternative gendered practices, shaped by novel experiences of male and female bodies which do not conform to the essentialist categories productive of an immutable sexual hierarchy. It is in this regard that mixed-sex sports might be seen as important for feminist understandings of physical culture. Doing away with sex as an organizing principle, they can afford participants with embodied experiences predicated more or less on physical equality between groups of men and women, the likes of which sex-segregated sports cannot, by definition, provide. And while it is true that such sporting experiences may potentially re-affirm essentialist beliefs about male physical superiority - for instance, when men beat women at various sports or when integrated contests feature different rules concerning men's and women's performances ${ }^{8}-$ evidence from recent studies suggests that this potential has, to a point, begun to be realized. ${ }^{9}$

In this paper, I offer an exploration of the underpinnings of mixed-sex participation in martial arts, detailing the particular discourses which surround such activities and help to legitimize their break from normative models of segregation. I begin by briefly detailing the ways in which this form of inclusivity exists in martial arts training cultures, discussing the limited extent to which this promise of integration has been realized. I then focus on attempting to outline how this is made possible, exploring the specific, somewhat unique meanings of these physical cultural settings with regard to media representations, 'female-appropriate' adaptations, and pedagogical focuses among various styles of martial arts.

\section{Method}


The body of data informing this paper is drawn from two qualitative studies of mixed-sex martial arts conducted in the English East Midlands during the years 2007-11. The first of these studies was conducted within a single kung fu club, involving combined participant observation and interviewing of club members and instructors. The second was a wider study of several different martial arts clubs across the region, based on interviews with a series of long-term practitioners. In addition to these research methods, the studies were informed by my personal experiences of martial arts participation, having practiced freestyle kickboxing and shaolin kung fu over a combined period of seven years. ${ }^{10}$

Interviewee selection was based on observations of club training in the first study, within which my situated position as a regular member of the training group helped to facilitate easy access to a range of participants. Meanwhile, 'snowball' sampling was used in the second study, beginning with personal contacts and enquiries at a few local training centres, eventually leading through a range of martial artists at a number of different clubs. Interviewees were prioritized on the grounds of experience, with 3 years' continuous training as a minimum requirement. Topical, semi-structured, one-to-one interviews were used in both studies, which were then transcribed and thematically coded before being analysed, with follow-up interviews held in order to clarify findings. To ensure privacy and prevent potential bias, interviews were either held away from interviewees' training centres, or within them at times when no other club members were present. Following transcription, interviewees' names were changed, using self-selected pseudonyms to protect their anonymity.

In total, 37 interviewees took part across both studies, including 17 men and 20 women. With an age range of 18-43 for the men and 18-32 for the women, the mean ages of both groups were 26 and 24 respectively. It is possible to describe the sample as being predominantly 'middle-class'; 32 had gained an academic or vocational degree, or were currently studying for one, and many worked in knowledge-based or specialist skilled jobs (e.g. accountant, school teacher, etc.). Most of the interviewees self-identified as being White British, although two of the men identified as Black British, while three men and three women identified as British Chinese, one man British Asian and one woman mixed-race (British/Japanese). Finally, all of the interviewees identified as being heterosexual.

Of further note is that these interviewees represented 15 different martial arts clubs and 11 distinctive martial arts disciplines between them, including choi kwang do, judo, jujitsu, karate, kickboxing, kung fu, mixed martial arts (MMA), muay thai, taekwondo and taijiquan. Furthermore, almost all of the interviewees had trained at other clubs previously, and often in other martial arts disciplines. ${ }^{11}$ As such, the sample of interviewees from these two studies is considered to consist of martial arts aficionados, whose collective experiences represent a diverse range of knowledge about training at various different types of martial arts, including more 'traditionalist' Eastern styles as well as ostensibly more 'Westernized' variants. ${ }^{12}$ Thus, the research data discussed here is largely concerned with practitioner experiences and discursive constructions of martial arts in a general sense, rather than within any specific (sub)cultural setting. 


\section{Integrated training environments in martial arts}

Previous discussions of mixed-sex sport have tended to claim that sex segregation is virtually ubiquitous across all forms of (Western) sports, so much so that even feminist scholars have failed to adequately recognize or criticize it. ${ }^{13}$ Despite 'Western history (being) replete with examples of women competing against men in sport', the examples of the past are thought to often be forgotten, as segregating the sexes from an early age is such a normalized practice that it has become one of sport's most taken-for-granted principles. ${ }^{14}$ However, having spent several years training, and subsequently researching various martial arts, such segregation was far from normal in my experience of contemporary martial arts training cultures in the UK. Indeed, the majority of interviewees taking part in my research noted that 'coercive sex segregation' was rarely, if ever, seen in their own training environments. ${ }^{15}$ Rather, it was sex integration that was seen as 'normal', even if this appeared odd to practitioners at first:

When you first walk in... you don't expect women to be there, but after a while when you've done it enough, it's normal... (I wonder) why aren't there more people doing it, more women doing it? (Ed, muay thai competitor)

All of the clubs I've trained in have been mixed-sex, it's quite normal I think... Yeah, all of them, training together, it's normal. (Steve, kung fu instructor)

Indeed, the 'normality' of women's involvement in martial arts, and their participation alongside men in particular, has been reported in other recent studies, notably in the relatively new (and highly 'masculinized') combat sport of MMA. ${ }^{16}$ Even in boxing, a sport historically considered synonymous with orthodox expressions of masculinity and the concurrent exclusion of women, there is evidence that women and men are sharing training spaces and, in some cases, training together. ${ }^{17}$

The extent of this integration is not always 'complete' though, as practical or symbolic differentiations between men and women persist in many cases, such as in Lafferty and McKay's and Mennesson's accounts of gendered discriminatory practices in Australian and French boxing gyms. ${ }^{18}$ For many of those interviewed in the course of my research, practices which most directly foregrounded practitioners' physicality, such as 'conditioning' exercises or competitive sparring, were thought more likely to be segregated - although this was often qualified not simply in terms of sexual difference, but relative to a noted correlation between sex and size. ${ }^{19}$ However, practices which involved directly hitting could become particularly problematic, as conceptions of essential female weakness, along with the requirements of masculine honour, made 'men hitting women' a distinctly difficult prospect for some men to manage. ${ }^{20}$

Nevertheless, in some cases, even such practices as these were integrated. For instance, several interviewees told me how women, particularly when preparing for competitions, 
would spar at high intensity with male opponents, while mixed sparring in training, at lighter intensities, was a typical element of all of my interviewees' experiences. ${ }^{21}$ In addition, many told of women taking coaching and other leadership roles in their clubs, being widely accepted by male and female practitioners alike, which stands in contrast to other instances of women's coaching of men in sport. ${ }^{22}$ Many interviewees also described their clubs having made deliberate efforts to market themselves to women, and of generally welcoming the atmosphere of mixed-sex environments, seen as broadly beneficial for training. ${ }^{23}$ Finally, some even described instances of mixed-sex sparring competition at tournaments, with many of those who had such experiences being eager to see them become more common. 'Brazilian' jujitsu competitor and part-time MMA coach Rachel described her feelings after having won second place in the 'men's' division of her weight category at a grappling competition:

I want women to be allowed to fight with men... If anything what I've done so far shows you how putting us in different divisions is like, well it's stupid to begin with.

Thus, not only are women involved at multiple levels of participation in martial arts, they are also commonly training alongside men, frequently attaining coaching positions in mixed-sex clubs, and in some cases, even competing against men at tournaments. Having asked a range of experienced male and female martial artists to explain this, the most typical response by far was that sex integration in training was simply 'normal'. Some even went further, stating that it was also justified as being true to the central meanings of martial arts. According to kung fu instructor Evelyn:

It's all the same, men and women together, yeah, and it should be like that. We don't want to make things different and make it look like women need to do a softer or weaker thing because that would really go against a lot of what kung fu is about.

It may seem surprizing that this level of inclusivity exists within a set of practices which are largely concerned with enhancing and measuring practitioners' ability to fight, as fighting is often considered a classically 'masculine' occupation in orthodox Western gender discourse. ${ }^{24}$ Relative to the normalization of segregation seen elsewhere in Western physical culture, this discursive framing of sex integration in martial arts as 'normal' is, therefore, quite abnormal. How is it then, that when sex segregation is thought to be so widespread and normalized elsewhere, that it is considered to 'go against' what martial arts is 'really all about'? What shapes the normative parameters of martial arts training cultures in ways which legitimate or promote this form of inclusivity? In the following sections I discuss how the unique cultural location of martial arts in the UK provides the discursive underpinnings for justifying the normalization of this integrated practice.

\section{Martial arts mythologies: kung fu movies and orientalist legend}


Arguably, the popularity of Eastern martial arts in many Western countries today owes much to the success of 'kung fu' movies, a notable sub-genre of action cinema popular since the latter half of the twentieth century. ${ }^{25}$ Iconic Asian actors including Bruce Lee, Jackie Chan and Jet Li, along with Westerners such as Jean-Claude Van Damme, Steven Seagal and Chuck Norris, brought disciplines including aikido, karate, wushu, and derivative styles such as kickboxing, to the cultural mainstream. Importantly though, on-screen martial artistry has not been limited to male action heroes; movies depicting women's use of martial arts, often against men, have also proliferated over the past half-century, including in 1960s exploitation films (e.g. Faster Pussycat! Kill! Kill!, 1963), Hong Kong action dramas (Yes, Madam, 1985), historical wuxia epics (Crouching Tiger, Hidden Dragon, 2000), and Hollywood blockbusters (Kill Bill, 2003-2004). In addition, television shows from as early as the 1960s and 1970s (The Avengers; Charlie's Angels), through to the 2000s and beyond (Buffy the Vampire Slayer; Nikita), have featured female protagonists whose highly stylized proficiency in martial arts is a central dynamic of their roles, more often than not used to subdue larger, stronger, and better armed male assailants. Finally, martial arts videogames have also extensively featured female fighters, beginning with Street Fighter II (1991) but now seen in all major fighting game franchises (Mortal Kombat; Soul Calibur; Tekken; etc.), with their inclusion premised upon the fact that they are an even match for the games' male characters.

For lack of space, I cannot here attempt to unpack the multiple gendered meanings of women in action media, which often involve (hetero)sexualization, racial stereotyping, or reactionary patriarchal narratives; compelling analyses of such things have been offered elsewhere. ${ }^{26}$ However, what all these depictions of (specifically female) martial artistry have in common is an emphasis on the superiority of technical fighting mastery - the somewhat hidden, internal capabilities of the body - over physical size or strength - its most outwardly visible, and almost always sexed, characteristics. Here, the typical association between (male) sex and (superior) physical power is rendered meaningless, as the discursive construction of martial arts as a technical system which transcends other elements of physicality takes precedence in determining one's combative ability. Such depictions are very often divorced from reality, such as with explosive 'special moves' in videogames and computer-generated imagery/'wirework' in film. ${ }^{27}$ Yet the exaggerations of martial arts media speak to the underlying discourse permeating much martial arts practice: anybody, regardless of size or strength - and thus by extension, sex - can become an accomplished fighter provided they dedicate themselves to mastering their body's latent combative potentials. In this regard, many interviewees described how their consumption of martial arts media helped inspire participation or make sense of men's and women's abilities:

I always thought (martial arts were) quite cool actually, exciting... like The Karate Kid, I love it... When I was growing up these movies made me feel like anyone could do it. (Andrea, choi kwang do practitioner)

In the (martial arts) games, the women have different fighting styles, like they're always smaller and faster, and in a way it's quite accurate because martial arts training is based on what you can do with your own body type... Games and films (featuring women) are more 
accurate because they show you how martial arts isn't just for like, big, strong men. (Bob, kung fu practitioner)

Often an important element of 'kung fu' media, the 'Asian' roots of many popular martial arts systems also represent a unique discursive resource for breaking with typical Western assumptions about sex, physicality, and fighting ability - and thus making sense of sex integration in training. 'Orientalist' understandings of Asia pervade contemporary discourse about cultural practices imported to the West from this region, such that 'orientalism remains an important backdrop to the collective social meaning of Eastern movement forms in the West today, and to the experiences and behaviours of its practitioners'. ${ }^{28}$ Broadly conceiving of 'the East' as an exotic place shrouded in mystery, the status of the 'other' conferred by this popular cultural mythology partly legitimizes the otherwise peculiar practice of sexintegrated martial arts in particularly Eastern disciplines, as practitioners recognize an incompatibility between Eastern traditions and modernist, Western conceptions of a clearly demarcated gender order. According to kung fu and MMA practitioner Gavin:

When it comes to kung fu, in the East anyway, there's a lot of female activity in it... you got a lot of females doing it. It's like in the East (martial arts) is ok for females, they don't think it's just a male thing... It's a different culture, different traditions, I guess they don't think about (sex) like (Westerners) do so they bring it over here and carry on offering it to females.

For some, this cultural difference was explained as an effect of an historical legacy of women warriors who, in the legendary history of Eastern martial arts, had played pivotal roles in their development. Kung fu and jujitsu practitioner David described his perception of the normative status of women in martial arts with reference to the legendary history of wing chun kung fu, which helped make sense of, in particular, the role of women as coaches or instructors of male practitioners: ${ }^{29}$

I think there is a history of (women teachers), because traditionally in Chinese kung fu, there are some styles like wing chun for example, it was created by a woman, designed for women, and they obviously taught men how to do it too... So women have always been in martial arts, and especially wing chun, well it is really popular in lots of countries and it was invented by a woman so I guess (women teaching men) is quite normal.

In these regards, the mythologized meanings of martial arts are quite different from other sporting activities, in that they are regularly depicted in various mediated forms as being somewhat 'sex-neutral' (although rarely gender neutral, given the often feminized or masculinized aesthetics of videogame and film characters, for instance). They are also often described with recourse to orientalist discourses stressing the exotic 'otherness' of the East, removing them from the historical/cultural milieu out of which masculinist, modern Western sport arose. This sets the various martial arts disciplines in a somewhat unique position, as the major discursive structures which define the practices in the media (technical mastery trumps size and strength; Eastern mysticism defies supposedly rationalized, Western cultural norms) create possibilities to imagine the body, and thus invitations to physically perform, in relatively unique ways, marking out integrated training as a more acceptable proposition. 
However, women's presence in martial arts has also been framed by meanings less foreign to Western gender typologies, which also have some bearing here.

\section{Female versions: non-combative arts and feminine fighters}

'Female-appropriate' sports are those which are culturally valued for being predicated upon the enhancement or measurement of typically 'feminine' (bodily) characteristics. ${ }^{30}$ Variously differentiated from 'men's sports', they have historically served as sites where women can participate in sporting recreation without posing an overt challenge to the assumed 'natural' hierarchy between the sexes which sports are otherwise implicated in supporting. In this regard, the gender-troubling phenomenon of women's desire to be involved in sport is diffused, as their participation in activities which emphasize, measure or enhance 'femininity', and thus difference from men, becomes a means of further entrenching the patriarchal norm of binary and hierarchal sex difference, rather than challenging it. ${ }^{31}$ Some forms of martial arts practice have developed into such female-appropriate activities, principally via their adaptation into non-combative fitness programmes designed at enhancing women's heterosexual attractiveness.

Women's participation for the purposes of 'fitness' in fact represents a typical form of entry into the wider cultural space of martial arts. Hargreaves notes that since the 1980s, noncombative forms of boxing - such as 'boxercise' aerobics - have become a popular form of workout for women, as the training was seen to help produce a desirably firm, shapely, yet 'feminine' body. ${ }^{32}$ Coupled with popular media representations of 'feisty', (hetero)sexy female martial artists, this generates an appeal among young women who may otherwise not have been interested in such ostensibly 'masculine' activities. Indeed, for many of the female interviewees in my research, the attraction of martial arts as a comprehensive workout system, good for 'toning up' the muscles and 'losing weight', was a compelling factor which initially drew them to clubs, also forming a key marketing tool for coaches wishing to expand their female clientele:

It's all these celebrity workout videos isn't it, they think (martial arts exercise) is gonna make them fit, and it's got that (fitness) image now, for women anyway... it's a good way to sell it to them. (Travis, kung fu instructor)

I definitely wanted to lose weight, that was important to me, it's helped a lot and I do feel a lot more confident with my body... And you see it in the films don't you, the Charlie's Angels thing, girls fighting and looking hot, I like that sort of thing, yeah, it's cool. (Keeley, kickboxing practitioner)

However, rather than confining such 'feminine' forms of participation within a female-only space, the existence of this fitness-oriented version of martial arts could, in turn, become a gateway for women to go on to participate in more combative forms of training. Commonly, this was explained as a function of enjoying the activity to the extent that women wanted to 
experience it in its fullest form and meet their own greater potentials as martial artists. Kickboxing instructor Amir described how:

Women come here for the fitness really, and then when they realize how good they are they might want to take the next step (and become competitive fighters). Some of them get the bug, and that's all they wanna do then, fight.

For such women, transitioning from 'fitness' to 'fighting' did not mean leaving behind the feminine aesthetics for which they initially entered the training environment. Rather than seeing themselves as adopting a form of 'female masculinity', they continued to emphasize (heterosexual) femininity through their appearance, clothing/kit, or other interests, whilst also remaining 'serious' about their training. Thus, for these women, combative martial arts and femininity could be effectively reconciled:

I don't know anything that's as close to how much I love (martial arts), like, I just love it, I love being able to do this... (but) I still love to have a sense and a feel of being a girl. I'm not embarrassed about fighting... but at the same time I still like to have some sort of girliness into it, so I have my hot pink gloves, it's quite cool, things like that... People definitely still see me as a girl, yeah. (Sylvia, muay thai and MMA competitor)

I teach pole dancing too, that's another part of me really. It's two extremes, isn't it! ...So I think through doing that I really explored my sexuality and everything, because I'm now teaching girls how to be feminine, and yet I'm a serious kickboxer... It's all a part of who I am. (Helen, kickboxing competitor)

Furthermore, the achievements of these visibly 'feminine' women were important in shaping others' attitudes towards inclusion and sex integration, as they would often prepare for competitive fights by training with male fighters. This was a product of another iteration of the gendered patterning of participation, as while the 'female-appropriate', fitness-oriented lessons offered by clubs primarily appealed to women, their more combative, competitive martial arts training sessions, which resonated more closely with socially idealized forms of masculinity, were disproportionately populated by men. ${ }^{33}$ Thus, because there were relatively few women involved in competitive martial arts, and training partners within one's weight category were therefore hard to come by within any given club, women who 'crossed over' this divide would often do their competition training - which typically involved high intensity sparring - with men. In addition to this, several interviewees also told of women competing in men's divisions at tournaments when too few female competitors entered, showing the degree to which combative participation alongside men could be opened to women. ${ }^{34}$

However, rather than being treated as 'honorary males', the increasingly visible example of successful, yet 'feminine' female martial artists who were capable of holding their own against men, held significance by laying down a precedent of 'normal' women taking part in otherwise 'masculinized' training practices. This perception was shared among male and 
female club members, as these 'feminine' fighters were seen to break with social stereotypes of 'butch' female athletes typically constitutive of heterosexist discourse: ${ }^{.35}$

I'd say that nine out of ten of (the women I train with) I'd see at the weekend in a nice dress, looking quite attractive actually. Even the better girls, like the ones who might compete, they're not really like any kind of textbook hard woman. They're quite womanly, feminine I guess... Just goes to show you that this is a sport for everyone. (Claude, kickboxing coach)

(We are) showing that normal everyday women are capable of doing something which a lot of people say we're not. I think it's a good thing what we're doing. (Rachel)

While this process may draw criticism from some quarters for implying that a 'compulsory heterosexuality' restricted such women's performances of gender, this was not how the women reported the experience, as feelings of personal agency in choosing to 'do' femininity simply for the enjoyment of 'being girly' was an important element in all of those interviewees' accounts. More pertinently however, their enduring femininity heralded a potent shake-up of essentialist sex discourse stressing the transgressive nature of women's embodiment of 'male' characteristics, such as fighting ability. Often interpreted as 'a pathological sign of (women's) misidentification and maladjustment', female masculinity risks the discursive annihilation of 'butch' girls as aberrant, probably homosexual, and thus not representative of 'real' women. ${ }^{36}$ Instead, combative martial arts participation among otherwise 'feminine' women revealed 'the power of being in a feminine-gendered body', troubling normative and exclusive conceptions of feminine heterosexuality. ${ }^{37}$

Whilst no doubt dependent upon the heterosexist frames of reference through which they were initially attracted to non-combative, 'female-appropriate' versions of participation, this gendered dynamic nevertheless provided a route for women to cross over into mixedsex/combative participation in ways which destabilized this heterosexism, revealing just what so-called 'normal', feminine women were capable of relative to their male counterparts. However, not all women initially took up martial arts as a 'female-appropriate' workout programme. For some, the attraction was based more in the self-defence application of martial artistry, which was also important for many men, being significant for both groups in structuring ideas about the inclusivity and integration of training.

\section{Alternative physical culture: self-defence and the rejection of 'masculinity'}

In many respects, martial arts are not sports. While many martial arts disciplines have become 'sportized' in both meanings and practice, a great variety of disciplines and schools continue to represent an alternative form of physical culture to the sporting mainstream in various Western contexts. ${ }^{38}$ Their diverse meanings and purposes leave open many different possibilities for making sense of martial artistry, and by extension, the gendered significance of participation. While much can be said about the possible philosophical, pedagogical, and cultural uniqueness of martial arts practice, two notable differences from mainstream sports 
cultures bear mention here for their role in helping legitimize mixed-sex inclusivity. These include self-defence readiness as a key outcome of (particularly women's) training, and the critical comparisons made between male practitioners' identities and supposedly 'mainstream', sporting masculinities.

The practice of martial arts for self-defence is today widely popular for both men and women. Much has been written by feminist sociologists about women's self-defence martial arts, broadly celebrating and advocating the practice as a form of liberation, empowerment and self-realization. ${ }^{39}$ However, while previous scholars have generally not directly highlighted the significance of mixed-sex training for helping reach such ends, and more often than not have advocated single-sex environments for their more woman-centred or explicitly feminist pedagogies, the martial artists I interviewed unanimously suggested that effective women's self-defence training was largely dependent upon sex integration. This principally reduced to a perceived necessity for women to practice with men in order for the training to be 'realistically' effective, based on conceptions of sex and violence which resonate with typical constructions of sex difference and the patriarchal norms of 'rape culture' which self-defence is meant to oppose. ${ }^{40}$

Firstly, women's self-defence training was considered more effective when they trained with men because of perceived size and strength differences, meaning that learning to escape from holds or take hits from men was necessary to push the boundaries of women's abilities:

If a guy grabs hold of you it's different to a girl grabbing hold of you, they can hold you tighter. So when you practice with the big guys that's more useful, more realistic to what a real situation would be like. I wouldn't expect a ten year old girl to grab my wrist on the street! (Andrea)

Similarly, and more commonly, the second reason for supporting integrated training also drew on this idea of 'realism', given that men were considered the most likely perpetrators of violence against women, and that such violence was thought common. This cast women's self-defence training as important within a social context where the risk of being (sexually) assaulted by a man was high, and wherein men's power to physically coerce women was more or less taken for granted. Therefore, training with men was psychologically important in preparing women to fight back, as most women would not believe themselves capable otherwise:

It's good for (women) to work with guys to get an idea of what it might be like to be attacked, because men are the most likely attackers. (David)

I think it's so important for us to learn how to stand up to a man physically... I'm not scared of that any more, since I've been sparring against men for years and I know what it's like to be hit (by them), I'm used to the confrontation. (Marie, kickboxing instructor) 
Such practicalities as these were made all the more urgent given that self-defence confers serious connotations on martial arts training, crediting it with enhancing one's personal safety ahead of potentially life-or-death situations. And unlike similar safety-enhancing physical activities, such as swimming, mixed-sex participation was required if this training was to be of any practical use for women. Legitimized as appropriate and necessary by a popular cultural discourse of women's vulnerability to male violence, such integrated training can also become a pathway to potentially subvert such discourse by revealing women's ability to resist men's violence, and thus rejecting the role of women as men's inevitable victims. In this regard, self-defence is a practice which is both embedded within the typical discursive parameters of patriarchy, but also aimed at overcoming the effects of such structures by transforming the ways in which women think about and perform within their bodies. ${ }^{41}$ The popularity of martial arts as self-defence for women thereby contributes significantly to the transformative potential of normalized, integrated training, as it is explicitly concerned with enhancing women's fighting abilities relative to men's, and is thereby far removed from the typical constructions of sex difference common among segregated sports cultures more generally.

Further differentiation from other sporting activities revolved around the tendency for martial arts disciplines to have broader, more holistic pedagogical outcomes than the typically competitive focus of most Western sports. ${ }^{42}$ With reference to this distinction, particularly male participants in my research were critical of a form of masculinity which they believed to be commonplace among men involved in highly competitive, pedagogically narrow, and philosophically empty 'mainstream' sport. ${ }^{43}$ Distancing themselves from a confrontational, violent, and crude masculine style which they believed common in such other sports, and in particular the practice of sport as a means of 'proving' one's masculinity to others, they valorized an approach to training which was based around humility, introspection, and a dedication to self-improvement in various ways. ${ }^{44}$ This ultimately contributed to a broad rejection of a specific and supposedly widespread articulation of masculinity, and a male egotism seen by some as being harmful to the outcomes of training:

(Men) who do martial arts... they don't go around wearing it on their sleeves, "I do kung fu", that sort of thing. They're more subdued about it... Yeah, I think a real man isn't into superficial things... I guess a real man is someone who's respectful of everyone around him, accepting other people, not really into all that masculinity stuff. (Steve)

Guys with something to prove don't fit in here, it isn't right for (martial arts), isn't the right mentality... A lot of guys come in here with that ego, the big man ego... most of them drop out within a week. (Amir)

Such criticisms of other men's machismo, and broad rejection of 'masculinity' as an organizing principle of participation, contributed to the men's readiness to accept women as training partners. Unanimously agreeing that martial arts was not a 'manly' activity, or a 'man's sport', being valued as a fellow martial artist was thus based on sharing a set of 
idealized characteristics grounded in a focus on personal development and growth, which had nothing to do with one's sex: ${ }^{45}$

If your partner is more experienced, then whether they are a man or woman isn't important, because you can learn from anyone who's like, above you in skill level... It's all about how good they are at technique, movement, that kind of thing, and how much discipline they bring to their training, that's what makes a (training) partner useful. (Simon, karate practitioner)

Such a rationalization as this compares strikingly with the kinds of reactions to integrated sport suggested in previous studies, where the politics of gender within various other sports cultures rarely problematizes the masculinity of the male athlete. ${ }^{46}$ Here though, sex integration was considered logically compatible with the goals of martial arts training, regarding both the high-stakes, practical realities of self-defence, and the importance of focusing on personal development as the central purpose of the activity, rather than becoming fixated upon enhancing or proving one's masculinity. Thus, the focus of training philosophies stressing either the singular importance of developing martial competency, or holistic approaches to broader self-improvement, provided further discursive legitimacy for the normalization of sex integration.

\section{Discussion and concluding thoughts}

This paper has explored the discursive underpinnings of inclusion in mixed-sex martial arts, examining several features of martial arts cultures which legitimize the otherwise socially problematic practice of integrated training. These have included broader representations of martial arts; the pathways for crossover opened by sex-differentiated forms of training; and the practical and ideological separation of martial arts activities from mainstream sporting cultures. The meanings of these phenomena were sometimes connected to conservative constructions of sex difference, which otherwise might make integrated training difficult to imagine, yet through participants' simultaneous performance of other, martial arts-specific discourses, and within the practical necessities and realities of training, new and contradictory possibilities for action emerged. In this regard, and while I have not discussed this in great detail here, the reciprocal effect of practitioners' experiences of performatively embodying the possibilities represented by these discourses further normalizes integrated practice. Here, men's and women's joint performance of a discourse of equity and inclusion, through the shared, physical experiences of training, then becomes its own 'dramatic symbolic proof', just as segregated sport has long done for sexist ideals of exclusion. ${ }^{47}$

Yet, it is important to recognize that this inclusivity is not something which has simply sprung from the ground, paving the way for the performance of an altogether radical bodily practice through which otherwise entrenched ideals of fixed, binary, and hierarchal sex difference might be challenged and potentially undone. While the effects of men's and women's performances are vital in helping to shape out new discourses concerning sex, gender, and the body, understanding what first enables such performances is an important 
step in grasping how the transformative phenomenon of inclusive, mixed-sex sports participation can come about; thus have I focused here on the discourses and practices underlying this integration.

In helping to understand the importance of this perspective, queer feminist theory emphasizes the poststructuralist tenet that language is just as much a means of constructing social realities as of describing them. In this way, the physical reality of sex difference is something which individuals bring about, following their gendered performances of specific cultural scripts, or discourses. According to Butler, this perspective holds that 'there is no possibility of agency or reality outside of the discursive practices that give those terms the intelligibility that they have' ${ }^{48}$ If this be the case, then determining the underlying discursive parameters of integrated inclusivity in sports cultures is a vital first step in understanding how the radical social action represented by such practices is initially made possible. Without being able to draw on alternative schemes of intelligibility, the cyclical relationship between discourse and performance - in this case meaning conservative constructions of gender and segregated, hierarchal, and patriarchal forms of sport - would repeat itself ad infinitum. In the context of martial arts cultures, several important discursive structures exist which enable participants to perceive the world in ways which 'fall outside' of the otherwise widely normalized, takenfor-granted system of binary, hierarchal sexual difference. As these are put into practice, they provide alternative means for imagining, and then performing, the reality of living in a sexed body, such that following their logics can lead practitioners to accept the normalization of mixed-sex training as appropriate and even useful in a number of ways. Such performance can then help to realize the transformative promise of integrated sport, as discussed at the outset.

As such, I would suggest that efforts to understand sex integration in sports cultures should be attentive to the sources of this particular form of inclusivity in various contemporary settings. While previous studies have explored the role of legal and policy interventions in imposing such inclusion 'from above', I have here outlined how normalized, integrated inclusion has emerged more or less 'from the ground up', by exploring the relatively unique features of contemporary martial arts training cultures in the UK which are supportive of this inclusion. ${ }^{49}$ My analysis here is somewhat limited, in terms of its demographic bias (i.e. predominantly middle-class, heterosexual, young adult Britons), present-centeredness, and focus on martial arts-specific discourses rather than wider, contemporary social attitudes towards sex and gender. While further research efforts could help to better locate such findings as these within their broader socio-cultural and historical contexts, the apparent importance of the unique meanings of martial arts in participants' constructions of mixed training as 'normal' (and even appropriate), nevertheless reveals the importance of examining the roots of such practices within their specific social locations. I would suggest, therefore, that future endeavours in exploring sex-integrated sport would do well to look not only to the effects of such phenomena on practitioners' embodiment, identities, and beliefs, but also to the underlying discursive structures which facilitate their existence and acceptance in the first place. In so doing, a knowledge base will emerge from which future efforts at transforming 
the widely entrenched norms of default, sex-segregated sport may be able to draw potentially useful insights.

\section{Notes}

1 Hargreaves, Sporting Females; Roth and Basow, 'Femininity, Sports, and Feminism'; Theberge, 'Sport and Women's Empowerment'.

2 Wachs, 'Levelling the Playing Field'; Henry and Comeaux, 'Gender Egalitarianism'; Anderson, 'I Used to Think'; Guérandel and Mennesson, 'Gender Construction'; Love and Kelly, 'Equity or Essentialism?'; Travers, 'The Sport Nexus'.

3 McDonagh and Papanno, Playing with the Boys; see also Anderson, 'I Used to Think'; Fields, Female Gladiators; Messner, Power at Play; Messner, Taking the Field.

4 Bryson, 'Challenges to Male Hegemony', 175.

5 Butler, Gender Trouble; Haraway, Simians, Cyborgs and Women; Grosz, Volatile Bodies.

Messner, 'Sports and Male Domination'; Love and Kelly, 'Equity or Essentialism?', 228.

7 Butler, Gender Trouble, 32.

8 Wachs, 'Levelling the Playing Field'.

9 Anderson, 'I Used to Think'; Channon, 'Hit Me!'; McDonagh and Pappano, Playing with the Boys, 58-63.

10 See Channon, 'Do You Hit Girls?'.

11 In the following sections, interviewees are identified as practitioners of whichever discipline(s) they were involved in at the time of interview, along with their level of participation, categorized here as (noncompetitive) practitioner, competitor, or instructor.

12 Theeboom and De Knop, 'Asian Martial Arts'; Theeboom, De Knop and Vertonghen, 'Experiences of Children', 20.

13 Love and Kelly, 'Equity or Essentialism?'; McDonagh and Papanno, Playing with the Boys.

14 Travers, 'The Sport Nexus', 89.

15 That being when women are not allowed to participate in 'men's' sporting spaces - or vice versa - rather than voluntary segregation, wherein women/men elect to be separated. McDonagh and Papanno, Playing with the Boys, 7-8.

16 Abramson and Modzelewski, 'Caged Morality', 156-8.

17 Mennesson, 'Hard Women'.

18 Lafferty and McKay, 'Suffragettes in Satin Shorts'; Mennesson, 'Hard Women'; see also McCaughey, Real Knockouts, 79.

19 'Conditioning' typically involves partnered drills wherein participants strike one-another's limbs, head or torso repeatedly to toughen up the tissue and become familiarized with the pain of combat; see Spencer, 'Habit(us), Body Techniques'.

20 Channon, 'Do You Hit Girls?'; Guérandel and Mennesson, 'Gender Construction'

21 In the course of regular training, martial artists rarely use their full force to strike or throw, in order to minimize injury risk. In fact, being 'controlled' was considered an important attribute when working with partners, regardless of sex differences; the use of greater force was typically only legitimized in preparation for competitive fights. See Channon, 'Way of the Discourse', for a fuller discussion of these themes.

22 See Norman, 'Feeling Second Best'.

23 Channon, 'Way of the Discourse', 134-5.

24 e.g. Hirose and Pih, 'Men who Strike'; McCaughey, Real Knockouts; Messner, 'When Bodies are Weapons'.

25 Krug, 'At the Feet'.

26 e.g. Innes, Action Chicks; McCaughey and King, Reel Knockouts; Mikula, 'Gender and Videogames'.

27 Brown, Jennings and Leledaki, 'The Changing Charismatic Status', 184-5.

28 Brown and Leledaki, 'Eastern Movement Forms', 128.

29 The legend of Wing Chun was depicted in the 1994 movie of the same name, starring Michelle Yeoh; see Gomes, 'Doing it (Un)like'.

30 Caudwell, 'Sporting Gender'; Lenskyj, 'Power and Play'.

31 Roth and Basow, 'Femininity, Sports, and Feminism'.

32 Hargreaves, 'Women's Boxing'.

33 Even though male martial artists are often quick to deny that 'masculinity' is an important element of their practice - see below; also Mayeda and Ching, Fighting for Acceptance; Spencer, Ultimate Fighting.

34 See Rachel's quote, above.

35 See Caudwell, 'Femme-Fatale'. 
38 Brown and Johnson, 'The Social Practice'; Villamón et. al., 'Reflexive Modernization'

39 De Welde, 'Getting Physical'; Guthrie, 'Liberating the Amazon'; Hollander, 'I Can Take'; McCaughey, Real Knockouts.

40 McCaughey, Real Knockouts.

41 Ibid

42 See Brown and Johnson, 'The Social Practice'.

43 See Channon, 'Western Men' for a more detailed empirical analysis.

44 Ibid.

45 Abramson and Modzelewski, 'Caged Morality', 156.

46 e.g. Bryson, 'Challenges to Male Hegemony'; McDonagh and Pappano, Playing with the Boys; Messner, Power at Play; Messner, Taking the Field.

47 Messner, 'Sports and Male Domination', 200; for a more comprehensive discussion of the transformative outcomes of integrated martial arts training, see Channon, 'Way of the Discourse'.

48 Butler, Gender Trouble, 202.

49 Fields, Female Gladiators; Love and Kelly, 'Equity or Essentialism'.

\section{References}

Abramson, Corey M., and Darren Modzelewski. 'Caged Morality: Moral Worlds, Subculture, and Stratification among Middle-Class Cage-Fighters'. Qualitative Sociology 34, no. 1 (2011): 143-75.

Anderson, Eric. "'I Used to Think Women were Weak": Orthodox Masculinity, Gender Segregation, and Sport'. Sociological Forum 23, no. 2 (2008): 257-80.

Brown, David, George Jennings, and Aspasia Leledaki. 'The Changing Charismatic Status of the Performing Male Body in Asian Martial Arts Films'. Sport in Society 11, no. 2/3 (2008): 174-94.

Brown, David, and Alan Johnson. 'The Social Practice of Self-Defense Martial Arts: Applications for Physical Education'. Quest 52, no. 3 (2000): 246-59.

Brown, David, and Aspasia Leledaki. 'Eastern Movement Forms as Body-Self Transforming Cultural Practices in the West: Towards a Sociological Perspective'. Cultural Sociology 4, no. 1 (2010): 123-54.

Bryson, Lois. 'Challenges to Male Hegemony in Sport'. In Sport, Men, and the Gender Order: Critical Feminist Perspectives, edited by M. Messner \& D. Sabo, 173-84. Champaign: Human Kinetics, 1990.

Butler, Judith. Gender Trouble. Abingdon: Routledge. 1990.

Caudwell, Jayne. 'Sporting Gender: Women's Football Bodies as Sites/Sights for the (Re)Articulation of Sex, Gender, and Desire'. Sociology of Sport Journal 20, no. 4 (2003): 371-86.

Caudwell, Jayne. 'Femme-Fatale: Re-thinking the Femme-inine'. In Sport, Sexualities and Queer/Theory, edited by J. Caudwell, 145-58. Oxon: Routledge, 2006.

Channon, Alex. "'Hit Me!" Mixed-Sex Martial Arts and the Subversion of Gender'. Paper presented at the $6^{\text {th }}$ meeting of the Transnational Working Group for the Study of Gender and Sport, Bath, UK, November 2627, 2010.

Channon, Alex. 'Way of the Discourse: Mixed-Sex Martial Arts and the Subversion of Gender'. PhD diss., Loughborough University, 2012.

Channon, Alex. "'Do You Hit Girls?" Striking Moments in the Career of a Male Martial Artist'. In Fighting Scholars: Habitus and Ethnographies of Martial Arts and Combat Sports, edited by R. Sánchez García and D. Spencer. London: Anthem, Forthcoming.

Channon, Alex. 'Western Men and Eastern Arts: The Significance of Eastern Martial Arts Disciplines in British Men's Narratives of Masculinity'. Asia Pacific Journal of Sport and Social Science 1, no. 2-3 (2012): 1-17.

De Welde, Kristine. 'Getting Physical: Subverting Gender through Self-Defense'. Journal of Contemporary Ethnography 32, no. 3 (2003): 247-78.

Fields, Sarah K. Female Gladiators: Gender, Law, and Contact Sport in America. Chicago: University of Illinois Press, 2005. 
Gomes, Catherine J. 'Doing it (Un)like a Lady: Rethinking Gender in Martial Arts Cinema'. Graduate Journal of Asia-Pacific Studies 2, no. 1 (2004): 11-20.

Grosz, Elizabeth. Volatile Bodies: Towards a Corporeal Feminism. Bloomington: Indiana University Press. 1994.

Guérandel, Carine, and Christine Mennesson. 'Gender Construction in Judo Interactions'. International Review for the Sociology of Sport 42, no. 2 (2007): 167-86.

Guthrie, Sharon. 'Liberating the Amazon: Feminism and the Martial Arts'. In Women's Spirituality, Women's Lives, edited by Judith Ochshorn \& Ellen Cole, 107-20. NY: The Haworth Press, 1995.

Halberstam, Judith. Female Masculinity. London: Duke University Press, 1998.

Haraway, Donna. Simians, Cyborgs and Women: The Reinvention of Nature. New York: Routledge, 1991.

Hargreaves, Jennifer. Sporting Females: Critical Issues in the History and Sociology of Women's Sports. London: Routledge, 1994.

Hargreaves, Jennifer. 'Women's Boxing and Related Activities: Introducing Images and Meanings.' Body \& Society 3, no. 4 (1997): 33-49.

Henry, Jacques M., and Howard P. Comeaux. 'Gender Egalitarianism in Coed Sport: A Case Study of American Soccer'. International Review for the Sociology of Sport 34, no. 3 (1999): 277-90.

Hirose, Akihiko, and Kay Kei-Ho Pih. 'Men Who Strike and Men Who Submit: Hegemonic and Marginalized Masculinities in Mixed Martial Arts'. Men and Masculinities 13, no. 2 (2010): 190-209.

Hollander, Jocelyn A. “I Can Take Care of Myself”: The Impact of Self-Defense Training on Women's Lives'. Violence Against Women 10, no. 3 (2004): 205-35.

Inness, Sherrie A., ed. Action Chicks: New Images of Tough Women in Popular Culture. New York: Palgrave Macmillan, 2004.

Krug, Gary J. 'At the Feet of the Master: Three Stages in the Appropriation of Okinawan Karate into AngloAmerican Culture'. Cultural Studies $\leftrightarrow$ Critical Methodologies 1, no. 4 (2001): 395-410.

Lafferty, Yvonne, and Jim McKay. "'Suffragettes in Satin Shorts"? Gender and Competitive Boxing'. Qualitative Sociology 27, no. 3 (2004): 249-76.

Lenskyj, Helen. 'Power and Play: Gender and Sexuality Issues in Sport and Physical Activity.' International Review for the Sociology of Sport 25, no. 3 (1990): 235-45.

Love, Adam, and Kimberly Kelly. 'Equity or Essentialism? US Courts and the Legitimation of Girls' Teams in High School Sport'. Gender \& Society 25, no. 2 (2011): 227-49.

Mayeda, David T., and David E. Ching. Fighting for Acceptance: Mixed Martial Artists and Violence in American Society. Lincoln: iUniverse, 2008.

McDonagh, Eileen, and Laura Pappano. Playing with the Boys: Why Separate is not Equal in Sports. Oxford: Oxford University Press, 2008.

McCaughey, Martha. Real Knockouts: The Physical Feminism of Women's Self-Defense. London: New York University Press, 1997.

McCaughey, Martha, and Neil King, eds. Reel Knockouts: Violent Women in the Movies. Austin: University of Texas Press, 2001.

Mennesson, Christine. 'Hard' Women and 'Soft' Women: The Social Construction of Identities among Female Boxers'. International Review for the Sociology of Sport 35, no. 1 (2000): 21-33.

Messner, Michael. 'Sports and Male Domination: The Female Athlete as Contested Ideological Terrain'. Sociology of Sport Journal 5, no. 3 (1988): 197-211.

Messner, Michael. 'When Bodies are Weapons: Masculinity and Violence in Sport'. International Review for the Sociology of Sport 25, no. 3 (1990): 203-20.

Messner, Michael. Power at Play: Sports and the Problem of Masculinity. Boston: Beacon Press, 1992.

Messner, Michael. Taking the Field: Women, Men, and Sports. Minneapolis: University of Minnesota Press, 2002.

Mikula, Maja. 'Gender and Videogames: The Political Valency of Lara Croft'. Continuum 17, no. 1 (2003): 7987.

Norman, Leanne. 'Feeling Second Best: Elite Women Coaches' Experiences'. Sociology of Sport Journal 27, no. 1 (2010): 89-104. 
Roth, Amanda, and Susan A. Basow. 'Femininity, Sports, and Feminism: Developing a Theory of Physical Liberation'. Journal of Sport and Social Issues 28, no. 3 (2004): 245-65.

Spencer, Dale C. 'Habit(us), Body Techniques and Body Callusing: An Ethnography of Mixed Martial Arts'. Body \& Society 15, no. 4 (2009): 119-43.

Spencer, Dale C. Ultimate Fighting and Embodiment: Violence, Gender and Mixed Martial Arts. London: Routledge, 2011.

Theberge, Nancy. 'Sport and Women's Empowerment'. Women's Studies International Forum 10, no. 4 (1987): 387-93.

Theeboom, Marc, and Paul De Knop. 'Asian Martial Arts and Approaches of Instruction in Physical Education'. European Journal of Physical Education 4, no. 2 (1999): 146-61.

Theeboom, Marc, Paul De Knop, and Jikkemien Vertonghen. 'Experiences of Children in Martial Arts'. European Journal for Sport and Society 6, no. 1 (2009): 19-35

Travers, Ann. 'The Sport Nexus and Gender Injustice'. Studies in Social Justice 2, no. 1 (2008): 79-101.

Villamón, Miguel, David Brown, Julián Espartero, and Carlos Gutiérrez. 'Reflexive Modernization and the Disembedding of Judo from 1946 to the 2000 Sydney Olympics'. International Review for the Sociology of Sport 39, no. 2 (2004): 139-56.

Wachs, Faye Linda. 'Leveling the Playing Field : Negotiating Gendered Rules in Coed Softball'. Journal of Sport and Social Issues 26, no. 3 (2002): 300-16. 